\title{
Hybrid algorithm for the solution of the periodic vehicle routing problem with variable service frequency
}

\author{
Sergio Esteban Vega-Figueroa ${ }^{a}$, Paula Andrea López-Becerra ${ }^{a}$ and Eduyn R. López-Santana ${ }^{a^{*}}$
}

${ }^{a}$ Grupo de investigación Adquisición y Representación de Conocimiento mediante Sistemas Ex-pertos y Simulación (ARCOSES), Facultad de Ingeniería, Universidad Distrital Francisco José de Caldas, Bogotá, Colombia

\begin{tabular}{l}
\hline C H R O N I C L E \\
\hline Article history: \\
Received May 52021 \\
Received in Revised Format \\
June 282021 \\
Accepted October 22021 \\
Available online \\
October, 2 2021 \\
\hline Keywords: \\
PVRP \\
Clustering \\
Metaheuristics \\
Routing \\
Scheduling
\end{tabular}

\section{A B S T R A C T}

\begin{abstract}
This document addresses the problem of scheduling and routing a specific number of vehicles to visit a set of customers in specific time windows during a planning horizon. The vehicles have a homogeneous limited capacity and have their starting point and return in a warehouse or initial node, in addition, multiple variants of the classic VRP vehicle routing problem are considered, where computational complexity increases with the increase in the number of customers to visit, as a characteristic of an NP-hard problem. The solution method used consists of two connected phases, the first phase makes the allocation through a mixed-integer linear programming model, from which the visit program and its frequency in a determined planning horizon are obtained. In the second phase, the customers are grouped through an unsupervised learning algorithm, the routing is carried out through an Ant Colony Optimization metaheuristic that includes local heu-ristics to make sure compliance with the restrictive factors. Finally, we test our algorithm by performance measures using instances of the literature and a comparative model, and we prove the effectiveness of the proposed algorithm.
\end{abstract}

\section{Introduction}

Complexity in business environments grows over time because of technological advances and the dynamics of the economic system, for this reason, organizations of all kinds must constantly work on solutions that allow solving problems at strategic, tactical, and operational levels. Among the activities to be carried out at a tactical and operational level is allocating resources in the medium term and or short-term and scheduling tasks such as vehicle routing, which due to the level of detail of information and scalability corresponds to a problem difficult to solve. These activities of distribution and transport of goods or services have a high influence on their quality and can mean a high cost for the logistics management of organizations, which added to the context of increased demand for this type of services and competition it requires an adequate level of service and high operational performance in terms of costs. For this reason, the different and multiple factors that influence the problem of combinatorial optimization of vehicle routing problem (VRP) must be taken into account, which consists of finding the best route to visit a set of geographically distributed customers, with a specific fleet of vehicles that has a specific starting and ending point, to address this type of problem there are different solution methods, ranging from exact heuristics, metaheuristics and methods derived from artificial intelligence to stochastic modeling and new forms of representation of NPHard type problems, which even combine different solution methods and seek to take advantage of each of these. This article presents a proposed solution to a periodic vehicle routing problem (PVRP), which considers the minimum frequency of visits to customers in a given planning horizon as well as capacity limitations of the vehicle fleet and the customer's time windows, through a two-phase iterative model, using optimization techniques in the first phase where the allocation of customers is made for visiting the set of vehicles in each of the periods, while in the second phase performs a grouping by customers and uses the ant colony optimization (ACO) metaheuristic for routing supported with local heuristics for compliance with * Corresponding author

E-mail: erlopezs@udistrital.edu.co (E. R. López-Santana)

2022 Growing Science Ltd. doi: $10.5267 /$ j.jijiec.2021.10.001 
constraints, the phases are interconnected with exit procedures in case of infeasibility.

This paper is organized as follows. Section 2 presents a background section and a review of the literature related to the variants of the problem to be addressed and the different solution techniques, Section 3 describes the general structure of the problem and its representation. Next are sections 4, 5, and 6, dedicate to each of the phases of the proposed model where the mathematical formulation and the solution method are represented, Section 7 shows the design of experiments that supports the establishment of parameters to be used within the applied metaheuristic, Section 8 provide the results of the model verification compared instances of literature. Finally, the conclusions and recommendations for future work are presented in section 9 where the most relevant findings of the proposal made are consolidated.

\section{Background and literature review}

The VRP has historically evolved with contributions from the literature that mainly highlights the need for a solution to real situations. The contribution made by Dantzig \& Ramser (1959) represents the first case of formulation and generalization of the VRP through an optimal routing of trucks for the delivery of fuel from a depot to a set of service stations. The variant of time windows within this problem (VRPTW) moves forward with the rendering of a timetable for drivers of the massive mail fleet in central London. Pullen, H. \& Webb (1967) employ a heuristic routine that sought to reduce downtime between jobs. The work of Christofides \& Eilon (1969) uses basic restrictions such as vehicle capacity and distance or time to travel. They consider methods such as branching and bounding, the savings approach, and the optimal three-path approach to address the problem at hand. The work of Russell (1977) is relevant within the literary contributions found, this includes important restrictions such as capacity, distance, and time through the development of a heuristic called M-tours, where M means a number of vendors who make tours of the city, with better results obtained until then by the heuristics Sweep, Clark and Wright, Cluster First and Man-Machine, among others, Rodriguez, Correa \& López (2015). The first periodic vehicle routing problem for a given planning horizon was performed by Russell \& Gribbin (1991) where they present an approach for determining effective vehicle routes that satisfy customer service frequencies in the planning horizon, through heuristics in four phases, analysis and initial solution, cost exchange with the traveling salesman problem, cost reduction by addressing real routes and entire modeling for final improvements.

Some of the relevant applications of periodic vehicle routing are documented in the contribution of (Gulczynski et al., 2011), they propose a new way of solving the PVRP considering the objective of minimizing the differences in the allocations to calendars, however, they are proposed as restrictions and not as objectives (Puras \& Bonrostro, 2016) using in the initial solution mixed-integer programming, onwards denoted MIP. The authors use the Clarke \& Wright savings algorithm that provides good solutions capable of supporting robust problems. The development of the algorithm begins with the initial solution, savings heuristics, and record to record method, later it is adapted to solve the PVRP-RC and PVRP-BC problems, that correspond to restrictions of strong and soft reallocations and with limited allocations, as well as load balancing, other contributions that include periodic vehicle routing in their development are Méndez et al., (2005), Mourgaya and Vanderbeck (2007) and Cacchiani et al. (2014). Cordeau and Maischberger (2012) present a parallel iterated tabu search heuristic, to solve four variations of VRP, including periodic, time-window, multi-depot (MDVRP), and site-dependent vehicle routing (sitedependent VRP) the method uses an iterative local search framework (ILS), which generates sets of neighbors with attraction points, the initial solution varies depending on the VRP variant used, a random component or an insertion heuristic is used to obtain it, the taboo search starts with the current solution and a simple perturbation mechanism to ensure search space exploration. Zhao and $\mathrm{Lu}$ (2019) investigate and propose a solution to the problem of routing vehicles with an electric fleet, including capacity restrictions, time windows, and vehicle recharging needs, with a heuristic approach based on adaptive local search in large neighborhood accompanied by MIP, heuristics are intended to reduce the loading and the waiting costs. Among the other variants found in the literature stand out Reyes (2016) who present an optimization model for route scheduling for a logistics company with operations in Lima-Perú, which includes variables important to the problem such as time windows and mixed vehicle fleet size (FSMVRPTW). The split delivery VRP was studied by Batsyn, Batsyna, Bychkov \& Pardalos (2019), with a two-phase algorithm that seeks to solve the problem, addressed from a vehicle allocation problem (VAP), in which in the first phase a clustering is done and later the routing. Schneider \& Nurre (2019) develop a solution with a multicriteria approach for scheduling audits to beneficiaries of the United States food bank, taking into account trained vehicles and multiple time windows CVRPMTW, using exact and heuristic methods, within the contributions with different variations of the VRP found in the literature are Cattaruzza et al. (2016), Ben-Said et al. (2016), Muñuzuri et al. (2016), Froger et al. (2019) and Avellaneda et al. (2019).

The solution techniques to deal with the vehicle routing problem include exact methods, heuristics, metaheuristics, stochastic methods, hybrid algorithms, and expert systems, within the first group of solution methods, the most used techniques correspond to relaxation and diagrams of branching and bounding, dynamic programming, and column generation methods widely studied by Laporte and Nobert (1987). Recognized heuristic methods have also emerged in the literature, such as the Clarke \& Wright in 1964 which is part of the construction methods found so far in the literature, which consists of the comparison of two or more routes, which combined can produce savings in distance as long as they comply with the restrictions of the problem, it can be done in parallel or sequential, for this heuristic, there are variants such as the one based on matching or coincidence Olivera (2004), some improved versions are found in the contributions of Laporte (1997) and Toth \& Vigo (2002) when they generalize through a parameter in a way that penalizes joining with distant customers. 
Rocha Medina et al. (2011) present a literature review of methods as allocate first-route after, route first-allocate later, the sweep heuristic, and local search insertions heuristics. Insertion heuristics create the solution as they include customers for each iteration, it has the disadvantage that the last customers are generally dispersed among themselves increasing the cost, the variants of this method are the sequential insertion of Mole \& Jameson and a parallel insertion of Christofides, Mingonizzi and Toth, in which parameters are added to expand the route under construction in the first case and the second by two phases that improve the results by adding compact routes and creating them. Within the literature these contributions in heuristic solution methods also stand out (Chu et al., 2005; Torres Prato et al., 2015; Castillo et al., 2018).

On the other hand, metaheuristic techniques have had a growing and diversified evolution and historical development with various studies dating from 1985 according to Melian \& Moreno-Vega (2003), These general heuristic modeling strategies are mainly classified as trajectory, population, general, and others such as constructive, decomposition, long-term memory, and relaxation. Some of the investigations found in the literature on different metaheuristics and applications are the Taboo Search (TS) introduced by Glover in 1986 and developed by Cordeau, Jean-François Gendreau \& Laporte (1997), Simulated Annealing (SA) (Osman, 1993), ACO Bell, J.E. \& McMullen (2004), and evolutionary algorithms (EA) Baker, B.M. \& Ayechew (2003). Yousefikhoshbakht and Khorram (2012) propose a two-phase algorithm in which in the first instance it applies a sweeping algorithm (Sweep), in which the polar coordinates of the location of each customer are used and the smallest angle of a feasible arc is determined to generate a complete route with all customers, a sensitivity analysis is carried out with the faces to be used and tests that later demonstrate an ACS to solve a classic VRP problem that seeks to minimize the total distance traveled by vehicles in the second phase, three local search options are also used to improve the solution, exchanging nodes for each vehicle achieving good execution times and better solutions concerning the cited literature. Patiño, Daza \& López (2016) present a heuristic and optimization method to address a selective solid waste collection problem in Bogotá city, they are based on allocating first using sweep heuristics, allocation based on geometric centers and a proposed location model, and then route with a mixed-integer programming model. Orrego, Ospina \& Toro (2016) present a two-phase algorithm, which provides a solution to the vehicle routing problem, through a sweep heuristic to perform grouping and allocation of customers by vehicle and a genetic algorithm of Chu Beasley (AGCB). The last guarantees a diverse population throughout the convergence process, a single individual is replaced with new characteristics and is empowered by calibrating the parameters or determined operators. Barreto Riaño (2019) proposes a metaheuristic algorithm to solve the vehicle routing problem for a meat product distribution company, including time window restrictions and heterogeneous capacity (HFVRPTW) the search for an initial solution is made using the extended saving method, and subsequently, the SA algorithm is used, in which penalty approaches are considered for non-feasible solutions, diversification strategies during the local search for the concept of granularity, intensification based on criteria to accept movements and a disturbance procedure to leave local optimum. Among the applications with ACO algorithms to the VRP, there are several contributions. Cheng \& Mao (Cheng \& Mao, 2007) use ACS to solve traveling salesman problems with time windows (TSPTW), implementing local heuristics to include the restrictions or time windows to the problem, tests are carried out in instances known in the literature and their operation is verified in the problem. Creput, Hajjam, Koukam \& Kuhn (2012) deal with the problem of VRP with dynamic demand, customers can require the service at any time throughout the day, using a hybrid algorithm, implementing a neural network of the self-organized map called elastic mesh, which when compared with ACO, genetic and multi-approach algorithms get good solutions at a lower computational cost. Rodríguez-Vásquez, López-Santana, \& Méndez-Giraldo (2016) study a scheduling and routing problem for workers who provide a messaging service to a set of geographically distributed customers, the capacity of the fleet and the windows time are considered as the expiration dates and distance limitations through a three-phase method where they apply a programming model to determine the visit dates. Following this, the authors applied an expert system based on the know-how of the messaging service, starting with the clustering for each period through the characterization of algorithms based on centroids and finally an ACO method for the routing model applied to a case study of courier services.

The literature review carried out shows the need and growing trend of methods that add multiple characteristics to the problems of vehicle routing and that have large-scale application capacity, so this represents a contribution of application of different techniques that have been applied successfully and that allow to include different variables to the problem, which makes it a solution method applicable to different real situations.

\section{Problem statement}

We consider a set of customers $(N i)=\{1,2, \ldots, N T\}$ determined by the instances used, a set of Vehicles $(V)=\{1,2, \ldots, N V\}$ who carry out the visit that is assigned within a planning horizon defined by periods $=\{1,2, \ldots, H T\}$ considering the possible infeasibility of a solution is considered this triggering inside the criteria. The construction of the route is carried out taking as a reference the existing arcs between each of the customers allocated to each period, these arcs are defined between each subindex $i, j \in N i$. This implies that it is necessary to allocate customers to visit in each period of the horizon and then determine the route that each vehicle should take to minimize the total management and routing cost. Table 1 introduces the mathematical notation used in the phases of the model. To analyze the problem, the following assumptions are made:

- Standard service time for each customer and vehicle.

- $\quad$ Routing costs are calculated concerning the distance traveled. 
- The route of each vehicle begins and ends at the point of dispatch or depot.

- Using hard time windows, i.e., if the vehicle arrives earlier at the service point must wait until the moment when the window opens.

Fig. 1 states the flow chart of the proposed model to solve the problem raised above that is made up of two phases and two procedures carried out in case of non-feasibility. In addition, the details of each phase, its objective, function, inputs, and outputs, as well as the solution method, are summarized in Fig. 2.

Table 1

Notation used for allocation, clustering, and routing models

\begin{tabular}{ll}
\hline Sets: & \\
\hline$N i:$ & Set of customers index in $\mathrm{i}$ \\
$V:$ & Set of vehicles index in $\mathrm{v}$ \\
$P E:$ & Set of periods index in $\mathrm{k}$ \\
\hline Parameters: & Number of customers \\
\hline$N T:$ & Number of vehicles \\
$N V:$ & Number of periods (days) including the fictitious day \\
$K T:$ & Cost per unit missing relative to the desired amount of customer collection $i$ \\
$C f_{i}:$ & Cost per unit of excess over the desired amount of customer collection $i$ \\
$C e_{i}:$ & Customer demand $i$ on day $k$ \\
$P_{i k}:$ & Desired quantity of transport for customer $i$ \\
$Q d_{i}:$ & Transport capacity on day $k$ in vehicle $v$ \\
$C a p_{k v}:$ & Initial inventory of customer planning horizon $i$ \\
$I I_{i}:$ & Minimum customer frequency $i$ \\
$f m_{i}:$ & Large penalty value \\
$M:$ & Activation variable if customer $i$ is visited in period $k$ (Binary) \\
\hline Decision & Variables: \\
\hline$X_{i k}:$ & Activation variable if customer $i$ is visited in period $k$ with vehicle $v$ (Binary) \\
$Y_{i k v}:$ & Units missing for the desired amount of collection from customer $i$ on day $k$ \\
$U f_{i k}:$ & Units of excess for the desired amount of collection from customer $i$ on day $k$ \\
$U e_{i k}:$ & Customer service frequency $i$ in the planning horizon \\
$F_{i}:$ & Number of units accumulated at the end of period $k$ in customer $i$ \\
$I_{i k}:$ & Number of units to be transported in period $k$ for customer $i$ with vehicle $v$ \\
$Q T_{i k v}:$ & \\
\hline &
\end{tabular}

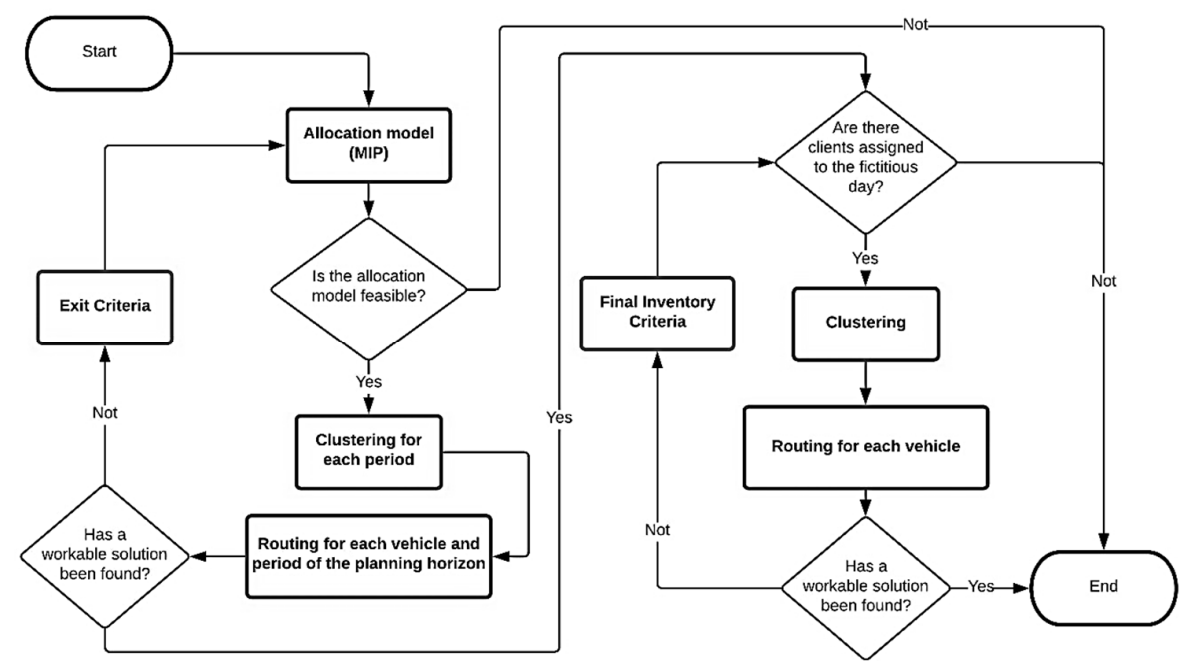

Fig. 1. Diagram of the proposed algorithm

\section{Phase 1 - Allocation model}

We use a mixed-integer programming model to get a schedule of visits for each customer during the planning horizon, where it seeks to reduce the total visit cost, considering the demand, the allocation of customers to each period of the horizon for the defined minimum frequency, and the missing or excess units. After that, if required, we define a fictitious day, which corresponds to an additional day in which it must be included in case there is infeasibility in the routing and therefore a change 
in the initialization values of the allocation model, this because of the penalty carried out within the exit criteria. When the allocation model is executed and it is feasibility this model provides the input information of phase number two, particularly the information related to the allocated customers for each of the periods contemplated is exported.

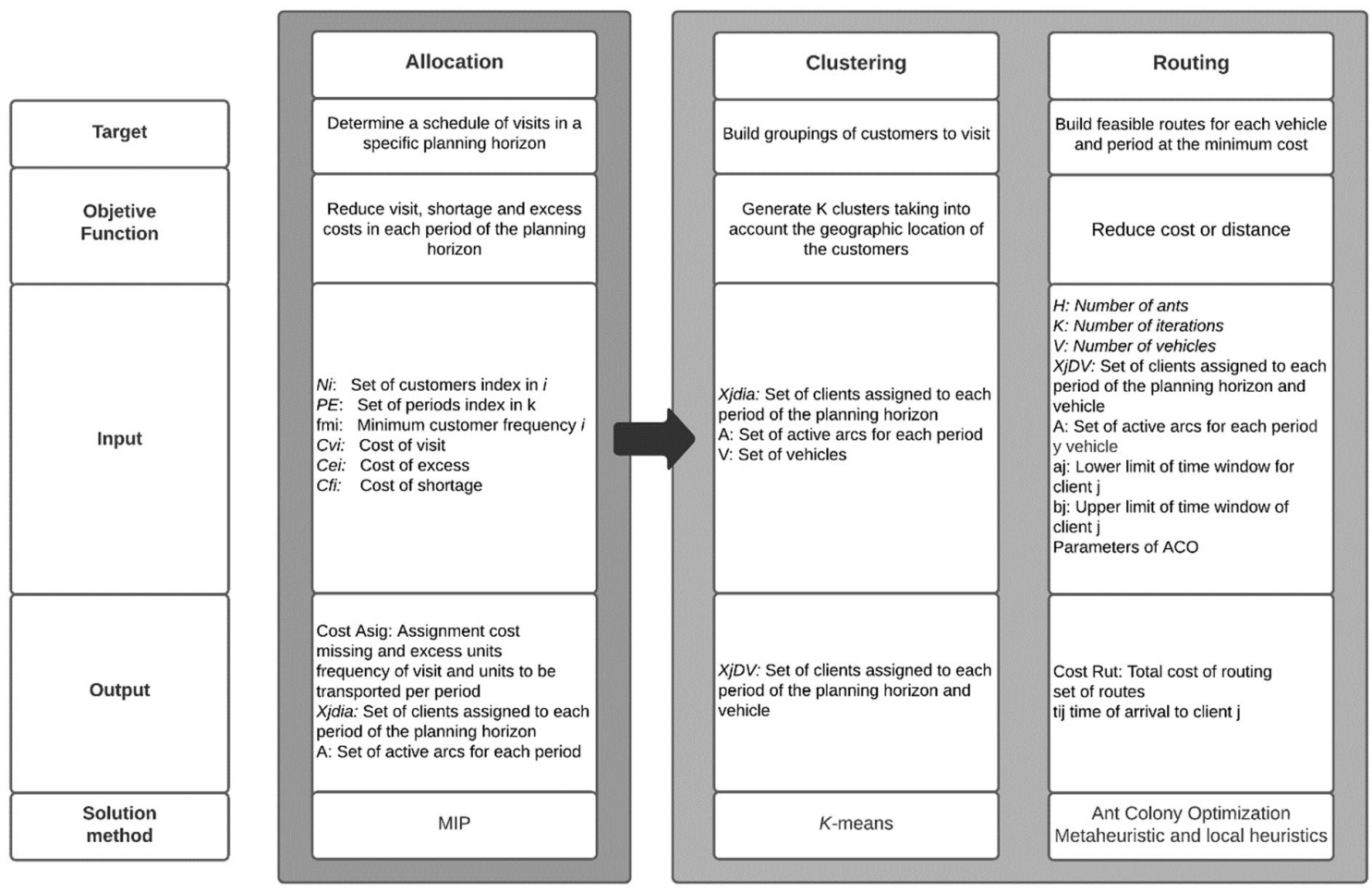

Fig. 1. Proposed solution approach to allocation and routing.

\section{Phase 2 - Routing Model}

The second phase begins by executing a clustering procedure that facilitates the adequacy of the data before entering the routing model. First, the algorithm receives as input information of geographical distribution and time windows of each customer as well as the customers grouped with the fleet of vehicles to be considered and the parameters corresponding to the model based on an ACO method with time window constraints, then, a bubble sorting procedure is carried out concerning the opening time windows of each already grouped cluster. The routing algorithm works iteratively for each day of the planning horizon (HT). In the same way, the route is formed through stages with procedures inspired by the behavior of ants within an ACO method, there the route is built taking into account the randomness in each of the mentioned stages and local heuristics where they determine the probability values per $\operatorname{arc}$ to meet each of the time windows for all existing $\operatorname{arcs}(i, j) \in A$ formed by NT customers and thus reach the best route according to the previously mentioned restrictive factors, once the best route is built by ant and iteration, the feasibility of the routes formed is evaluated, in case there is infeasibility during any of the days from the planning horizon, the exit criterion will be executed and in case of finding infeasibility on a fictitious day, then the final inventory criterion is executed.

\section{Exit criteria}

This procedure allows the two main phases of the algorithm to be connected and identifies the customers that may influence the infeasibility of the route of a vehicle during a day or several of the horizon planning, when it is executed, the cost of visiting the customer identified as problematic is penalized with the objective that that customer is not allocated to the day where there was infeasibility.

\section{Ending inventory criteria}

This procedure identifies the problematic customers in case of the routing for the fictitious day is infeasible, for that reason the problematic customers are exported to include them in the next planning horizon to fulfill the service of the customer in terms of demand and time windows.

Pseudocode 1 shows the algorithm to solve the problem using the method described above. In the next sections, we explain the formulation of the problem and the solution method or procedure, as well as the representation of the pseudocodes and a brief explanation of the interconnection criteria between phases. 


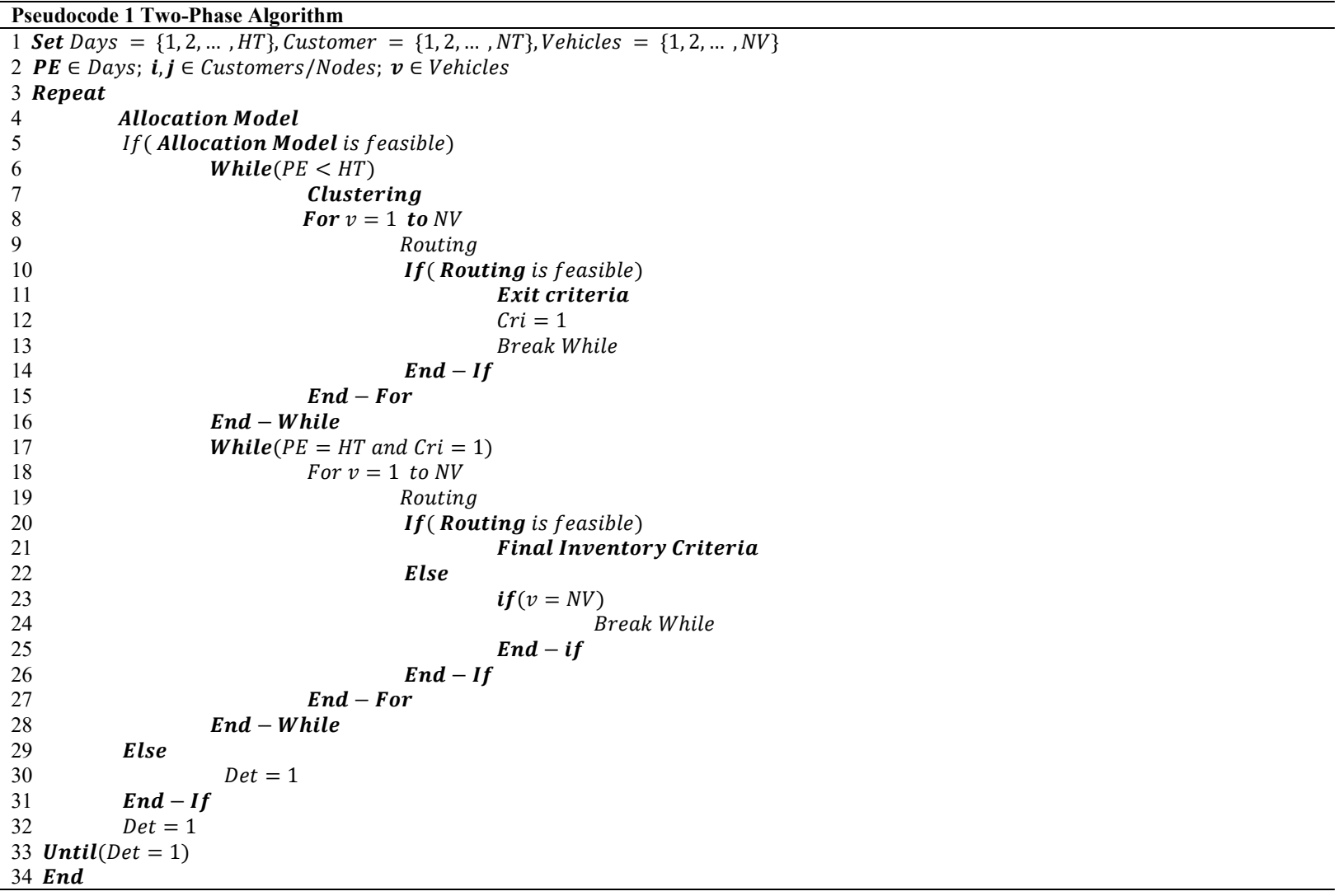

\section{First phase: Optimization allocation model}

There is a set of customers to visit in the planning horizon and a homogeneous fleet of vehicles, in this phase the allocation of visits to be executed for each period is carried out considering the allocated vehicles and their capacity as well as the minimum frequency of visits to each customer. In the following sections, emphasis is placed on the mathematical formulation and the solution method used.

\subsection{Problem formulation}

With a set $N i$ of customers for visiting that have a demand associated $P_{i k}$ during a planning horizon $H T$ and taking into account a fleet of $V$ vehicles with capacity $C a p_{k v}$, a variable $X_{i k}$ is defined as a binary type that takes the value of 1 if customer $i$ is visited in period $k$, otherwise, it will be 0 if it is not visited, which takes into account a value $C v_{i k}$ that is recognized as the cost of the visit. The model considers application cases with missing or excess inventory resulting from the activity of collection or distribution of goods or services, for which the variables are defined as $U f_{i k}$ and $U e_{i k}$ that count in terms of units the lack or excess concerning the desired quantity to be transported $Q d_{i}$ for a customer $i$ in the day $k$ that have associated cost parameters respectively $C f_{i}$ and $C e_{i}$ for each customer $i$. The objective is to minimize the total allocation cost, satisfying the demand and the minimum frequency of visits, considering the associated costs and, in the case of inventory, reducing the number of accumulated units $I_{i k}$ at the end of the planning horizon. The MIP model is formulated below:

$$
\operatorname{Min} \sum_{i \in N i}^{N T} \sum_{k \in K}^{K T}\left(C v_{i k} * X_{i k}+C f_{i} * U f_{i k}+C e_{i} * U e_{i k}\right)+\sum_{i \in N i}^{N T} \sum_{k \in K}^{K T-1}\left(C e_{i}+I_{i k}\right)
$$

subject to:

$$
\begin{aligned}
& \sum_{k \in K}^{K T-1} X_{i k}=F_{i} \quad \forall i \in N i \\
& F_{i} \geq f m_{i} \quad \forall i \in N i \\
& I_{i 1} \geq I I_{i} \quad \forall i \in N i \\
& P_{i k}+I_{i k-1}-\sum_{v \in V}^{N V} Q T_{i k v}=I_{i k} \quad \forall i \in N i, \forall k \in K \\
& I_{i k} \leq M\left(1-X_{i k}\right) \quad \forall i \in N i, \forall k \in K
\end{aligned}
$$


$Q T_{i k v} \leq M\left(Y_{i k v}\right) \quad \forall i \in N i, \forall k \in K, \forall v \in V$

$U f_{i k}-U e_{i k}=Q d_{i} * X_{i k}-\sum_{v \in V}^{N V} Q T_{i k v} \quad \forall i \in N i, \forall k \in K$

$\sum_{i \in N i}^{N T} Q T_{i k v} \leq \operatorname{Cap}_{k v} \quad \forall k \in K, \forall v \in V$

$\sum_{v \in V}^{N V} \sum_{i \in K}^{K T} Q T_{i k v}=\sum_{i \in K}^{K T} P_{i k}+I I_{i} \quad \forall i \in N i$

$Q T_{i k v} \leq \operatorname{Min}\left(\operatorname{Cap}_{k v}\right) \quad \forall i \in N i, \forall k \in K, \forall v \in V$

$X_{i k}=\sum_{v \in V}^{N V} Y_{i k v} \quad \forall i \in N i, \forall k \in K$

$X_{i k} ; U f_{i k} ; U e_{i k} ; I_{i k} \geq 0 \quad \forall i \in N i, \forall k \in K$

$Y_{i k v} ; Q T_{i k v} \geq 0 \quad \forall i \in N i, \forall k \in K, \forall v \in V$

The Eq. (1) represents the objective function where the total visit cost is calculated according to the values given by the decision variables, in the same way, the costs associated with the excess or missing units are added for each of the customers included in the problem, the second part of this formula represents the cost associated with the units that are in inventory since the customer $i$ visit was not carried out. The constraints (2) represent the computation of the frequency of visits allocated to each customer during the planning horizon without considering the fictitious day. The constraints (3) state that the visit frequency must be greater than or equal to the minimum visit frequency for all customers. In constraints (4) the initial inventory value is assigned for the first period of the planning horizon, said value is an input parameter to the model and represents the initial value of units at the beginning of the planning horizon of customer $i$. The constraints (5) are the balance constraints where the inventory values, demand, and quantities to be transported for each period and customer are related. In the model there is a group of switch-type constraints represented in the constrains set (6), which causes the activation of the inventory variable for the customer $i$ in the period $k$, there the parameter $\mathrm{M}$ is defined as a significantly large value to adequately penalize the restriction, this is also visible in the set of constraints (7) as a complement of the activation constraints if customer $i$ is assigned during period $\mathrm{k}$ with vehicle $\mathrm{v}$ and relates said activation with the quantities given for each indicated sub-index. The constraints (8) compute the difference of the excess or missing units and it must be equal to the difference between the sum of the transported units and the desired quantities to be transported. The representation of the capacity restrictions of each vehicle about the transported units assigned to each vehicle is given in constraints (9). The constraints (10) represent the balance between the quantities to be transported concerning the demand and the initial inventories at the beginning of the planning horizon for each of the customers. The constraints (11) state the units to be transported with the minimum capacity of the fleet of vehicles in case of heterogeneous capacity. The constraints (12) make that for the day on which a visit is allocated to each customer in a planning period, activation is guaranteed for a vehicle from those available within the fleet. In the constraint (13) and (14) are stated the nonnegative and type variables.

\subsection{Solution procedure}

The solution method used consists of the MIP model, previously formulated, implemented in the Xpress Mosel 5.0.2 and Xpress Optimizer software version 35.01.01 licensed, making use of the libraries or modules ("mmxprs", "mmive "," mmodbc "). This model was executed in an independent file and called from file number two that makes the execution of the model completely, integrating the two phases iteratively as illustrated in Fig. 1 and specified in Pseudocode 1.

\section{Second Phase: Routing model}

Once the customers have been allocated, an initial procedure was developed within the second phase that allows the active customers to be grouped in each period according to the visit schedule obtained. The proposed method was applied considering the data set selected for verification, which has the characteristic of a functional grouping by centroids that have unproblematic time windows between them.

\subsection{Clustering Problem formulation}

The algorithm splits a set of customers $N i$ with $x$ points in $v$ divisions, each of which is referenced according to a centroid $C$, what represents the mean $\mu_{j}$ of the data assigned to the division $v$. The objective of this algorithm is to determine centroids that reduce the criterion of the sum of squares within the cluster in the following way:

$$
\sum_{i=0}^{N i} \min _{\mu_{j \in C}}\left(\left\|x_{i}-\mu_{j}\right\|^{2}\right)
$$


Regarding the implementation of this proposal, there is a modification on the initialization of the centroids to obtain stable and feasible groups, this happens to depend on the number of vehicles available for routing and therefore the number $\mathrm{K}$ of clusters generated, when these are less than or equal to four, the initialization will be done on the extreme points formed by both the minimum and maximum values of longitude and latitude, that is, the centroids will be initialized in the geographically furthest points when it exceeds this number of extremes initialization will be given randomly. When a random initialization occurs, these extreme points are taken to generate said values according to the uniform distribution, using the inverse transform method to generate said random values and they are demarcated within the area where the customers are located, for which the points mentioned previously are used as the parameters $a$ and $b$ of uniform distribution. It is important to understand that the number of clusters is linked to the number of vehicles available for routing according to the day of the planning horizon.

$$
\begin{aligned}
& \text { Dist }_{\text {iv }}=\sqrt{\left(\text { Coorx }_{i}-\text { LonCent }_{v}\right)^{2}+\left(\text { Coory }_{i}-\text { LatCent }_{v}\right)^{2}} \forall \boldsymbol{i}, \boldsymbol{v} \\
& \text { LonCent }_{v}=\sum_{i \in N \mid X(i, D, v)>1}^{N T} \operatorname{Coor}_{i} / \sum_{i \in N \mid X(i, D, v)>1}^{N T} X(i, D, v) \forall \boldsymbol{v} \\
& \text { LatCent }_{v}=\sum_{i \in N \mid X(i, D, v)>1}^{N T} \operatorname{Coory}_{i} / \sum_{i \in N \mid X(i, D, v)>1}^{N T} X(i, D, v) \forall \boldsymbol{v}
\end{aligned}
$$

The model works iteratively updating the grouping of customers considering the closest centroid, through the calculation of the euclidean distance between each customer and each cluster, which is appreciable in the equation (16). Once the grouping is defined, the location of each of the centroids must be updated, this is done through the mean value corresponding to the longitude and latitude of the customers allocated to each cluster, represented in equations (17) and (18). The procedure is executed until the algorithm's stopping criterion is met, which is activated when the solution does not change, that is, the customers belonging to each cluster as well as the location of the centroids do not change.

\subsection{Clustering Solution procedure}

Pseudocode 2 presents the proposed clustering method corresponding to a K-means algorithm with initialization in extreme values.

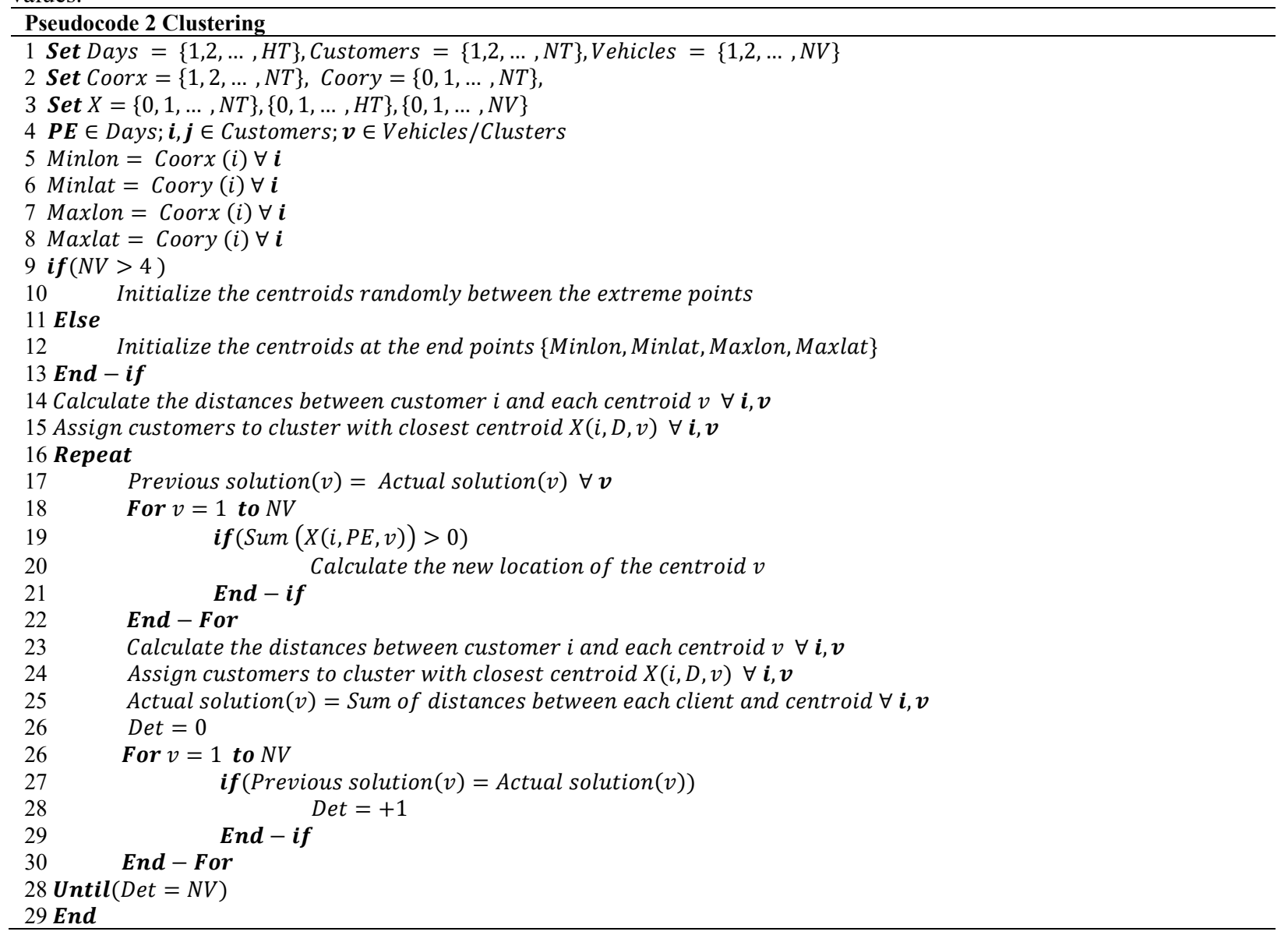




\subsection{Routing Problem formulation}

A procedure is performed of $K$ iterations for a set of ants $H$ whose function is to visit each of the customers of the group $N i$, which have associated the information corresponding to their location in terms of longitude Coor $x i$ and latitude Cooryi as well as lower visit time limits $a j$ and upper limits $b j$. The ants start and end at the initial node or reservoir, they travel the path through the active arches at a cost $C i j$ associated with distance at a given time $t j$ which is counted to perform the validation of time windows. The values of the initial parameters of the metaheuristics corresponding to the level of pheromone evaporation $\rho$ are taken into account, pheromone level between nodes $\tau i j$ and control of probability curves $\lambda$ and $\delta$ in the local heuristics $g i j$ and $h i j$ that increase the importance of near nodes to closing times Gij and opening $H i j$ of time windows. For each parameter that is taken into account in the probability weighting between nodes Prob there is a level of influence determined by the exponents $\alpha, \beta$, and $\gamma$, the Eq. (29) represents the update of the pheromone for each path and the expression (30) corresponds to the evaporation function of the pheromone that allows exploring new solutions and leaving optimal premises. Table 2 introduces all sets and parameters involved in our ACO method. The mathematical formulation with the local heuristics of time windows, probability calculation, update, and pheromone evaporation can be seen below:

$$
\begin{aligned}
& \text { Cij }=\sqrt{\left(\text { Coor }_{i}-\text { Coorx }_{j}\right)^{2}+\left(\text { Coory }_{i}-\text { Coory }_{j}\right)^{2}} \quad \forall i, j \mid i \neq j \\
& \text { Gij }=b j-t j \quad \forall i \in N i, \forall j \in N i \\
& H i j=a j-t j \quad \forall i \in N i, \forall j \in N i
\end{aligned}
$$

Table 2

Notation used for proposed ACO to solve the TSPTW

\begin{tabular}{ll}
\hline Sets: & \\
\hline$H:$ & Set of ants index in $\mathrm{h}$ \\
$K:$ & Set of iterations index in $\mathrm{k}$ \\
\hline Parameters: & \\
\hline$K T:$ & Number of iterations of the routing model \\
$N H:$ & Number of ants \\
$\rho:$ & Pheromone evaporation parameter \\
$\lambda:$ & Control of the probability curve in hij \\
$\delta:$ & Control of the probability curve in gij \\
$t j:$ & Actual time \\
$a j:$ & The lower limit of the time window to serve customer $\mathrm{j}$ \\
$b j:$ & The upper limit of the time window to serve customer $\mathrm{j}$ \\
$t s i:$ & Service time required on customer $\mathrm{j}$ \\
Coor $i:$ & Longitude coordinate of customer $\mathrm{i}$ \\
Cooryi: & Latitude coordinate of customer i \\
Cij: & Cost or distance between each of the nodes (Customers)
\end{tabular}


$\tau i j: \quad \quad$ Pheromone values between each of the nodes (Customers)

$\Delta \tau i j: \quad$ The exchange value of the pheromone on the best route (Intensification)

Prob: $\quad$ Probability between each of the nodes (Customers)

Heu: $\quad$ Cumulative value of local heuristics and thus weighting the probability

$\alpha: \quad$ Relative influence parameter of pheromone trace

$\beta$ : $\quad$ Heuristic information parameter derived from the time window

$\gamma: \quad$ Heuristic information parameter derived from the time window

gij: $\quad$ Local heuristics increase the importance of nodes near their closing time

hij: $\quad$ Local heuristics increase the importance of nodes close to their opening time

Gij: $\quad$ Time remaining for node $\mathrm{j}$ to close

$H i j$ : $\quad$ Time remaining for node $\mathrm{j}$ to open

$\mu: \quad$ The average value of the $\mathrm{Gij}>=0$

$\omega: \quad$ The average value of the $\mathrm{Hij}>=0$

Rutah: $\quad$ Sum of the solution distances Cij found by the ant $\mathrm{h}$

\subsection{Routing Solution procedure}

Pseudocode 3 summarizes the routing solution procedure using the ACO method described in the last section. Pseudocode 4 of an ordering procedure carried out on the groupings obtained from the clustering method is presented, which has the objective of contributing to the convergence to a feasible solution during routing.
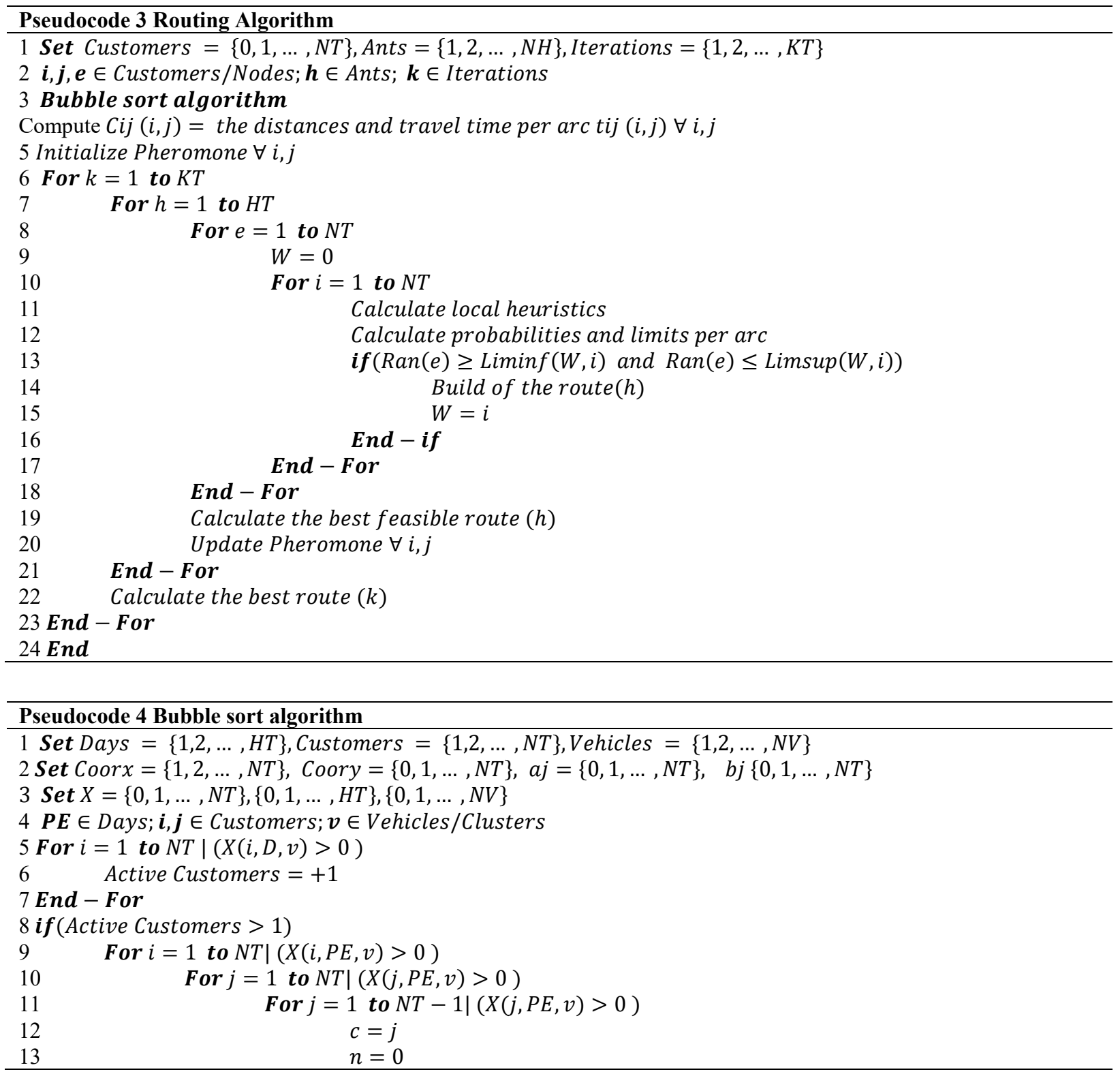


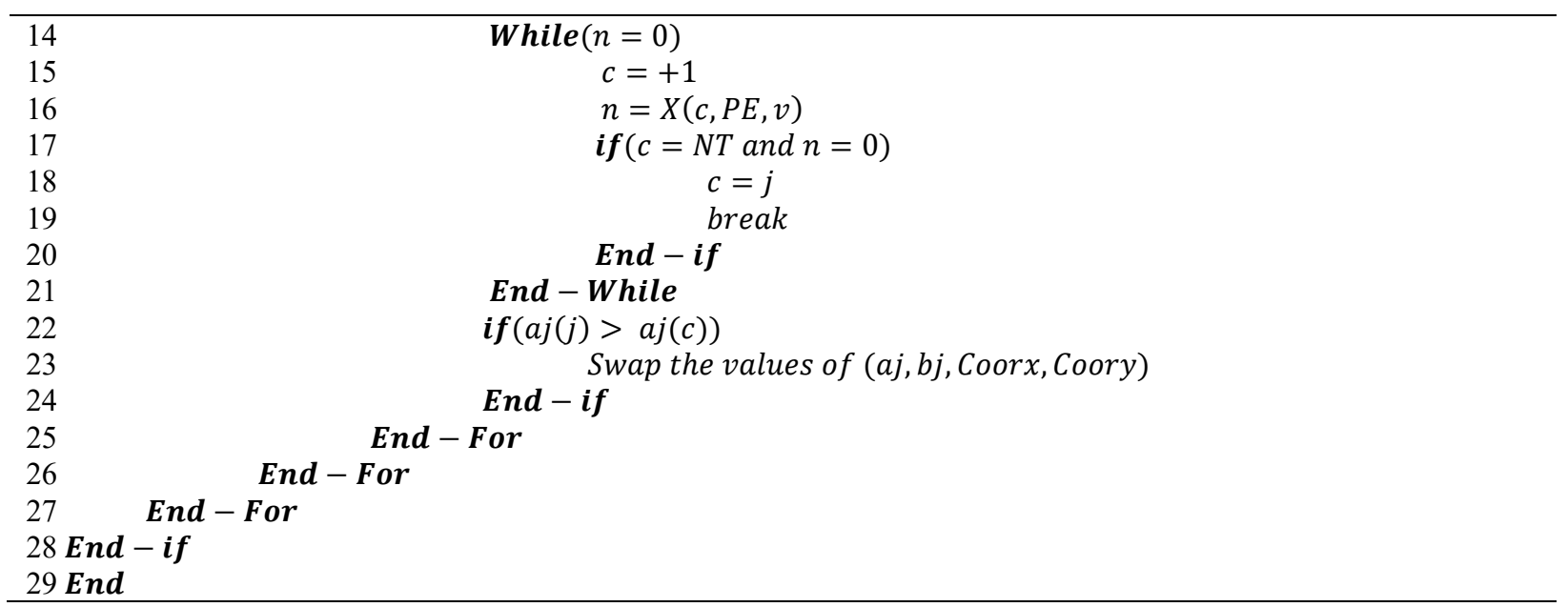

\section{Exit and ending inventory criteria}

The exit criteria and final inventory are based on the proposal made by Rodriguez, Correa \& López (2015) in which they identify infeasible customers during the routing phase, directing the flow of information to a new execution of the allocation phase after a penalty of the conflicting customer identified as the furthest point in terms of distance according to the expression (31):

$$
\text { Criteria }_{i}=\sum_{j \in N i \mid j \neq i}^{N T} C i j \quad \forall i \in N i \mid i \neq 0
$$

The input information about the allocation model is updated, the cost penalty is intended to generate a different schedule of views and the penalized customer is assigned to a different period.

\section{Experimental design for parameters of the second phase}

To achieve an adequate implementation of the routing model, we perform a set of experiments to establish the values of the parameters associated with the ACO metaheuristics with time windows, because these directly influence the performance of the algorithm. The parameters involved in the experimentation are, $N H, K T, \rho, \alpha, \beta, \gamma, \lambda$ and $\delta$ mentioned in

Table 2 those definitions are specified in Table 3. The possible values for each parameter were taken from Cheng \& Mao (Cheng \& Mao, 2007), which are summarized below :

Table 3

Parameter settings used in parameter values experiments

\begin{tabular}{cc}
\hline Parameter & Values to test \\
\hline$N H$ & $10,20,50,100$ \\
$K T$ & $10,20,50,100$ \\
$\rho$ & $0.1,0.3,0.5,0.9$ \\
$\alpha$ & $0.3,0.5,1,3$ \\
$\beta$ & $0.3,0.5,1,3$ \\
$\gamma$ & $0.3,0.5,1,3$ \\
$\lambda$ and $\delta$ & $0.01,0.03,0.05,0.07$ \\
\hline
\end{tabular}

The experimentation was carried out with two versions of the algorithm, which differ in the clustering initialization method, being of a random type or on the extreme values of longitudes and latitudes of the location of customer set, the data used was the group C107 of instances of Solomon with 25 costumers Solomon (1987). In addition, for each parameter, 16 different combinations were generated, with at least one different value and for each combination were executed 5 runs for a total of 1120 tests using two versions of the model. High variability was evidenced in the groupings of the version with random initialization that influenced convergence to infeasibility, as for the experimentation the parameters with the greatest influence on the results are the number of ants and iterations. In fact, the version was taken with initialization in extreme longitude and latitude values, the selected parameters were defined regarding the best performance in terms of the occurrence of a feasible solution, the best experimental solution, and execution times with the lowest experimental mean. The values selected for the parameters are $N H=50, K T=20, \rho=0.3, \alpha=0.5, \beta=0.5, \gamma=0.5, \lambda$ and $\delta=0.05$. Table 4 summarizes the performance of the selected values for each parameter in terms of the defined experimental measures. 
Table 4

Performance of values selected by the parameters

\begin{tabular}{|c|c|c|c|c|c|}
\hline \multirow[b]{2}{*}{ Parameter } & \multirow[b]{2}{*}{ Selected value } & \multicolumn{2}{|c|}{ Random initialization } & \multicolumn{2}{|c|}{ Initialization at endpoints } \\
\hline & & Gap \% units of distance & $\%$ Occurrence of feasibility & Gap \% units of distance & $\begin{array}{c}\% \text { Occurrence of } \\
\text { feasibility }\end{array}$ \\
\hline $\mathrm{NH}$ & 50 & $12,6 \%$ & $66 \%$ & $17,2 \%$ & $100 \%$ \\
\hline$K T$ & 20 & $11,0 \%$ & $14 \%$ & $17,2 \%$ & $79 \%$ \\
\hline$\rho$ & 0,3 & $8,9 \%$ & $9 \%$ & $17,2 \%$ & $82 \%$ \\
\hline$\alpha$ & 0,5 & $10,9 \%$ & $9 \%$ & $17,2 \%$ & $79 \%$ \\
\hline$\beta$ & 0,5 & $10,7 \%$ & $9 \%$ & $17,2 \%$ & $79 \%$ \\
\hline$\gamma$ & 0,5 & $10,2 \%$ & $14 \%$ & $17,2 \%$ & $82 \%$ \\
\hline$\lambda$ and $\delta$ & 0,05 & $11,6 \%$ & $64 \%$ & $17,2 \%$ & $93 \%$ \\
\hline
\end{tabular}

The comparison was made with the Rodriguez, Correa \& López (2015) model solution. It is observed that the version of the model with clustering with initialization in extreme values was taken mainly due to the ability to obtain a greater number of feasible solutions according to the experimentation carried out, even though with random initialization the solution could be improved in terms distance traveled.

\section{Results}

This section illustrates the results of the solution method presented to solve a routing problem with capacity and time windows through the comparison with the contribution made by Rodriguez, Correa \& López (2015), which corresponds to a two-phase model using exact methods interconnected iteratively through the exit and ending inventory procedures. The tests were carried out on a computer with a processor Intel Core i3 2.30 GHz and 4GB RAM, using Xpress Mosel 5.0.2 and Xpress Optimizer version 35.01.01 licensed that allows processing a greater number of variables and restrictions.

\subsection{Performance measures}

The performance measures used to verify the proposed method focus on the level of customer service, the use of resources, and the improvement of the logistics cost, and the efficiency of the method at the level of computational time.

\subsubsection{Customer service level}

This measure obtained from the allocation phase consists of verifying the fulfillment or satisfaction of the demand, through the measurement of the frequency of visits, it is expected that it will be the highest possible in the planning horizon, restricted by the minimum frequency of visit as appreciable in the equation (32), where the binary variable Xik is counted when a customer is visited in the period $k$.

$$
F=\sum_{i \in N i}^{N T} \sum_{k \in K}^{K T} X i k
$$

\subsubsection{Average vehicle utilization}

This performance measure evaluates the average utilization of the vehicle fleet capacity throughout the planning horizon, first, the vehicle utilization is found in each period $k$, it is calculated through the decision variable $Q T_{i k v}$ that indicates the units transported to customer $i$ with vehicle $v$ in period $k$ belong to the planning horizon and not to the fictitious day, for that reason it is defined for all $k$ that is different from the day mentioned.

$$
\begin{aligned}
& \text { Vehicle utilization }_{k}=\frac{\sum_{i \in N i}^{N T} \sum_{v \in V}^{N V} Q T_{i k v}}{\sum_{v \in V}^{N V} \operatorname{Cap}_{k v}} \quad \forall k \neq K T \in K \\
& \text { Average vehicle utilization }^{N}=\frac{\sum_{k \in K}^{K T-1} \text { Vehicle utilization }_{k}}{K-1}
\end{aligned}
$$

In Eq. (34) the calculation of the average use is made, where the sum of the use in all periods is found and it is divided into the number of periods that comprise the planning horizon without considering the fictitious day.

\subsubsection{Logistics costs}

The measurement of cost or distance traveled during routing to make the differentiation is presented below: 


$$
C T R_{k}=\sum_{i \in N i}^{N T} \sum_{j \in N i}^{N T} \sum_{v \in V}^{N V}\left(C i j * X_{i j v}\right) \forall k \in K
$$

In the same way, the total cost of the CTG logistics management will be counted as the sum of the allocation cost and the cost or total distance traveled $C T R_{k}$.

\subsubsection{Model efficiency}

The efficiency of the hybrid model will be evaluated in terms of the total execution time of the model, the percentage variation of the total cost of routing, and the total cost of logistics management.

\subsection{Instances}

The instances to be used were taken from Solomon (1987) groups specifically C101, C105, C106, C107, and C201, these have a characteristic of geographic location sectorized into groups, from there the coordinates are obtained $x$ and $y$ of each customer, the time between nodes is proportional to the distance between arcs, the demand, and the opening and closing time windows $a$ and $b$, the service time, which in this case is standard, and the capacity of the vehicle fleet. The rest of the data was replicated from Rodriguez, Correa \& López (2015), in order to carry out the comparison of the model, which correspond to the visit costs, excess costs, missing costs, which were generated from uniform distributions with parameters with at least one difference for each group, the initial inventory in all cases it is 0 , finally, the minimum restrictive frequency for the allocation phase was arbitrarily generated between multiples of the periods of the planning horizon.

\subsection{Numerical results}

The performance of this proposal was compared using groups of instances with different sizes of customers, specifically twenty instances of size of twenty-five nodes to visit were defined, in addition to this first comparison and to identify the advantages of the hybrid solution methods to manage a greater number of data or customers as well as determine proposals for improvement on the present work, tests were carried out with ten groups of instances of fifty customers and one hundred customers for each one, the representation of results is presented in the following subsections.

\subsubsection{Groups results from 25 customers}

In Table 5 is possible to observe the experimental results of the proposed model for each of the performance measures labeled Hybrid contrasted against the comparative model, where it can be observed that $60 \%$ of the groups of instances used the model proposed here reaches the comparative model solution that uses exact methods in the two phases.

Table 5

Performance comparison for groups of 25 customers

\begin{tabular}{|c|c|c|c|c|c|c|c|c|}
\hline \multirow[t]{2}{*}{ Instance } & \multicolumn{2}{|c|}{ Execution time (s) } & \multicolumn{3}{|c|}{ Routing cost (Monetary Units) } & \multicolumn{3}{|c|}{$\begin{array}{l}\text { Total cost of management } \\
\text { (Monetary Units) }\end{array}$} \\
\hline & Comparative Model & Hybrid & Comparative Model & Hybrid & VAR\% & Comparative Model & Hybrid & VAR\% \\
\hline C101 1-1 & 1,489 & 3,694 & 768 & 900 & $17,2 \%$ & 10.396 & 10.528 & $1,3 \%$ \\
\hline C105 1-1 & 2,251 & 3,45 & 768 & 900 & $17,2 \%$ & 13.436 & 13.568 & $1,0 \%$ \\
\hline C106 1-1 & 1,367 & 3,783 & 768 & 900 & $17,2 \%$ & 11.996 & 12.128 & $1,1 \%$ \\
\hline C107 1-1 & 2,026 & 3,364 & 768 & 900 & $17,2 \%$ & 13.476 & 13.608 & $1,0 \%$ \\
\hline C201 1-1 & 2,827 & 11,471 & 868 & 868 & $\mathbf{0 , 0} \%$ & 10.496 & 10.496 & $0,0 \%$ \\
\hline C101 1-2 & 1,117 & 3,813 & 768 & 768 & $0,0 \%$ & 24.956 & 24.956 & $0,0 \%$ \\
\hline C105 1-2 & 1,373 & 3,855 & 768 & 768 & $0,0 \%$ & 31.516 & 31.516 & $0,0 \%$ \\
\hline C106 1-2 & 0,922 & 3,769 & 768 & 768 & $0,0 \%$ & 30.516 & 30.516 & $0,0 \%$ \\
\hline C107 1-2 & 1,986 & 3,396 & 768 & 768 & $0,0 \%$ & 27.156 & 27.156 & $0,0 \%$ \\
\hline C201 1-2 & 4,273 & 7,16 & 868 & 868 & $0,0 \%$ & 25.336 & 25.336 & $0,0 \%$ \\
\hline C101 2-1 & 2,256 & 5,789 & 1.152 & 1.350 & $17,2 \%$ & 15.594 & 15.792 & $1,3 \%$ \\
\hline C105 2-1 & 3,167 & 5,267 & 1.152 & 1.350 & $17,2 \%$ & 23.394 & 23.592 & $0,8 \%$ \\
\hline C106 2-1 & 2,535 & 5,621 & 1.152 & 1.350 & $17,2 \%$ & 21.534 & 21.732 & $0,9 \%$ \\
\hline C107 2-1 & 3,69 & 5,784 & 1.152 & 1.350 & $17,2 \%$ & 23.574 & 23.772 & $0,8 \%$ \\
\hline C201 2-1 & 1,889 & 14,369 & 1.302 & 1.302 & $0,0 \%$ & 21.084 & 21.084 & $0,0 \%$ \\
\hline C101 2-2 & 1,749 & 5,98 & 1.152 & 1.152 & $0,0 \%$ & 56.274 & 56.274 & $0,0 \%$ \\
\hline C105 2-2 & 2,131 & 5,878 & 1.152 & 1.152 & $0,0 \%$ & 55.134 & 55.134 & $0,0 \%$ \\
\hline C106 2-2 & 1,747 & 5,714 & 1.152 & 1.152 & $0,0 \%$ & 61.914 & 61.914 & $0,0 \%$ \\
\hline C107 2-2 & 2,959 & 5,407 & 1.152 & 1.152 & $0,0 \%$ & 53.874 & 53.874 & $0,0 \%$ \\
\hline C201 2-2 & 1,783 & 13,397 & 1.302 & 1.302 & $0,0 \%$ & 56.424 & 56.424 & $0,0 \%$ \\
\hline
\end{tabular}

The cost difference is supported by the result of routing through the ACO algorithm in the grouping method, however, the variation of the total cost is less than $2 \%$ in all cases, in terms of the time of execution of the model, the difference is not significant despite presenting an increase and vehicle occupancy remains at the same levels in the models evaluated. 
In the execution of the model with groups of instances of fifty customers, it can be observed that some fields exceeded the level of processing allowed and it was not possible to find a feasible solution. At a general level, in Table 6 it can be observed that a better performance is obtained in the routing model solution in $80 \%$ of the evaluated cases where less distance is traveled, while in the remaining percentage a feasible solution is not obtained within the established time limit for the execution of the model.

Table 6

Performance comparison for groups of 50 customers

\begin{tabular}{|c|c|c|c|c|c|c|c|c|}
\hline \multirow{2}{*}{ Instance } & \multicolumn{2}{|c|}{ Execution time (s) } & \multicolumn{3}{|c|}{ Routing cost (Monetary Units) } & \multicolumn{3}{|c|}{$\begin{array}{c}\begin{array}{c}\text { Total cost of management } \\
\text { (Monetary Units) }\end{array} \\
\end{array}$} \\
\hline & $\begin{array}{c}\text { Comparative } \\
\text { Model }\end{array}$ & Hybrid & $\begin{array}{c}\text { Comparative } \\
\text { Model }\end{array}$ & Hybrid & VAR\% & $\begin{array}{c}\text { Comparative } \\
\text { Model }\end{array}$ & Hybrid & VAR\% \\
\hline C101 1-50 & 7,902 & 35,637 & 1.500 & 1.460 & $-2,7 \%$ & 19.468 & 19.428 & $-0,2 \%$ \\
\hline C105 1-50 & 11,398 & 42,058 & 1.500 & 1.460 & $-2,7 \%$ & 24.828 & 24.788 & $-0,2 \%$ \\
\hline C106 1-50 & 9,049 & 35,293 & 1.500 & 1.468 & $-2,1 \%$ & 26.268 & 26.236 & $-0,1 \%$ \\
\hline C107 1-50 & 14,876 & 35,393 & 1.500 & 1.460 & $-2,7 \%$ & 24.908 & 24.868 & $-0,2 \%$ \\
\hline C201 1-50 & 2,975 & - & 1.484 & - & & 17.252 & 15.768 & \\
\hline C101 2-50 & 12,53 & 56,266 & 2.250 & 2.190 & $-2,7 \%$ & 44.382 & 44.322 & $-0,1 \%$ \\
\hline C105 2-50 & 21,665 & 66,217 & 2.250 & 2.190 & $-2,7 \%$ & 46.782 & 46.722 & $-0,1 \%$ \\
\hline C106 2-50 & 20,891 & 66,005 & 2.250 & 2.202 & $-2,1 \%$ & 44.922 & 44.874 & $-0,1 \%$ \\
\hline C107 2-50 & 19,829 & 52,66 & 2.244 & 2.190 & $-2,4 \%$ & 51.816 & 51.762 & $-0,1 \%$ \\
\hline C201 2-50 & 5,315 & - & 2.226 & - & & 47.898 & 45.672 & \\
\hline
\end{tabular}

\subsubsection{Groups results from 100 customers}

For this group of instances, a relevant increase in execution time is observed, in $40 \%$ of the instances, a feasible solution was not reached, while in $30 \%$ of the solutions obtained a better performance was achieved due to the cost of routing or distance traveled and in the remaining percentage a not very significant increase for total cost purposes. Table 7 summarizes the results for this set of instances, where the application of the proposed algorithm to address larger data sets is demonstrated, however, the increase in execution time is related to a greater number of ants to guarantee the learning of the algorithm so that it reaches its respective solution.

Table 7

Performance comparison for groups of 100 customers

\begin{tabular}{|c|c|c|c|c|c|c|c|c|}
\hline \multirow{2}{*}{ Instance } & \multicolumn{2}{|c|}{ Execution time (s) } & \multicolumn{3}{|c|}{ Routing cost (Monetary Units) } & \multicolumn{3}{|c|}{$\begin{array}{c}\text { Total cost of management } \\
\text { (Monetary Units) }\end{array}$} \\
\hline & $\begin{array}{c}\text { Comparative } \\
\text { Model }\end{array}$ & Hybrid & $\begin{array}{c}\text { Comparative } \\
\text { Model }\end{array}$ & Hybrid & VAR\% & $\begin{array}{c}\text { Comparative } \\
\text { Model }\end{array}$ & Hybrid & VAR\% \\
\hline C101 1-100 & 85,185 & 472,72 & 3.356 & 3.340 & $-0,5 \%$ & 46.884 & 46.868 & $0,0 \%$ \\
\hline C105 1-100 & 269,54 & 484,2 & 3.356 & 3.392 & $1,1 \%$ & 50.004 & 50.040 & $0,1 \%$ \\
\hline C106 1-100 & 1200 & - & - & - & & 42.568 & 42.568 & \\
\hline C107 1-100 & 516,455 & 293,88 & 3.356 & 3.340 & $-0,5 \%$ & 50.764 & 50.748 & $0,0 \%$ \\
\hline C201 1-100 & 11,306 & & 2.400 & & & 43.928 & 41.528 & \\
\hline C101 2-100 & 298,449 & 515,58 & 5.034 & 5.010 & $-0,5 \%$ & 102.546 & 102.522 & $0,0 \%$ \\
\hline C105 2-100 & 319,193 & 471,66 & 4.998 & 5.010 & $0,2 \%$ & 105.210 & 105.222 & $0,0 \%$ \\
\hline C106 2-100 & 1200 & - & - & - & & 89.412 & 89.412 & \\
\hline C107 2-100 & 322,457 & 286,44 & 4.986 & 5.010 & $0,5 \%$ & 102.798 & 102.822 & $0,0 \%$ \\
\hline C201 2-100 & 20,604 & & 3.600 & & & 107.472 & 103.872 & \\
\hline
\end{tabular}

\section{Conclusions and future work}

The proposed algorithm fulfills satisfactorily the objective of the research, starting from a two-phase model that integrates solution methods such as the mixed-integer programming model for the allocation and a metaheuristic of ant colony optimization. We use the K-means clustering method for routing to get a solution that integrates the satisfied demand, the minimum frequency of visits, and the fulfillment of the time windows for each of the customers in most instances used for the results phase.

In the tests carried out for instances with a greater number of customers, we were able to improve the solution in terms of total distance traveled in respect to the model used for the comparison, while the cases where a feasible solution was not reached represent a minority within the study. It is attributed to the limitation of the clustering method conditional on initialization at extreme points and considering only the distance parameter between nodes. The use of exit criteria and ending inventory ensure adequate iteration between phases, the use of the bubble sorting algorithm accelerated convergence to a feasible solution, and the use of local heuristics positively influenced compliance with hard time windows during the routing phase. 
For future work, there are several insights from this research. First, the inclusion of other sophisticated and structured clustering algorithms that allows evaluating several characteristics and not only the distance between customers as in this case, to expand the application of the algorithm to other types of data understanding the existing need and possible variations in geographic densification or time windows. Secondly, there is an opportunity to improve the application of the second phase by establishing characteristics that allow reducing the number of iterations and individuals in the ant colony system, for example, elitist methods that allow the best performing ants to be selected. Other types of metaheuristics can also be applied in the second phase and in the allocation stage, which is where the least changes could be impacted in the present investigation. Finally, although the exit criteria and final inventory meet their objective, on these they could determine other solution methods that allow not having to execute the first phase and allow savings in computational resources.

\section{Acknowledgements}

We would like to acknowledge Fair Isaac Corporation (FICO) for providing us with Xpress-MP licenses under the Academic Partner Program subscribed with Universidad Distrital Francisco Jose de Caldas (Colombia).

\section{References}

Avellaneda, J., Estevéz, R., \& Aguilar, K. (2019). Un algoritmo colonia de hormigas para el problema de ruteo de vehículos eléctricos con función de carga parcial y ventanas de tiempo. Trabajo de Grado, 53(9), 1689-1699. https://doi.org/10.1017/CBO9781107415324.004

Baker, B.M. and Ayechew, M. A. (2003). A Genetic Algorithm for the Vehicle Routing Problem. Computer and Operation Research, 30, 787-800.

Barreto Riaño, H. (2019). Un algoritmo metaheurístico para solucionar el problema de ruteo de vehículos con restricciones de ventanas de tiempo y flota heterogénea en la empresa Carnes Los Sauces S.A.

Batsyn, M. V., Batsyna, E. K., Bychkov, I. S., \& Pardalos, P. M. (2019). Vehicle assignment in site-dependent vehicle routing problems with split deliveries. Operational Research, 0123456789. https://doi.org/10.1007/s12351-019-00471-7

Bell, J.E. and McMullen, P. R. (2004). Ant Colony Optimization Techniques for the Vehicle Routing Problem. Advanced Engineering Informatics, 18(1), 41-48.

Ben-Said, A., El-Hajj, R., \& Moukrim, A. (2016). An adaptive heuristic for the Capacitated Team Orienteering Problem. IFAC-PapersOnLine, 49(12), 1662-1666. https://doi.org/10.1016/j.ifacol.2016.07.819

Cacchiani, V., Hemmelmayr, V. C., \& Tricoire, F. (2014). A set-covering based heuristic algorithm for the periodic vehicle routing problem. Discrete Applied Mathematics (Amsterdam, Netherlands: 1988), $163(\mathrm{Pt} 1), 53-64$. https://doi.org/10.1016/j.dam.2012.08.032

Castillo, J. J. A., Giraldo, A. D. H., \& Cabrera, J. P. O. (2018). Método de dos fases para el problema de ruteo de mensajeros en motocicleta con ventanas de tiempo. Entramado, 14(1), $268-281$. https://doi.org/10.18041/entramado.2018v14n1.27106

Cattaruzza, D., Absi, N., \& Feillet, D. (2016). Vehicle routing problems with multiple trips. 4or, 14(3), $223-259$. https://doi.org/10.1007/s10288-016-0306-2

Cheng, C. Bin, \& Mao, C. P. (2007). A modified ant colony system for solving the travelling salesman problem with time windows. Mathematical and Computer Modelling, 46(9-10), 1225-1235. https://doi.org/10.1016/j.mcm.2006.11.035

Christofides, N., \& Eilon, S. (1969). An algorithm for the vehicle routing dispatching problem. Operations Research Quaterly, 20(3), 309-318.

Chu, F., Labadi, N., \& Prins, C. (2005). Heuristics for the periodic capacitated arc routing problem. Journal of Intelligent Manufacturing, 16(2), 243-251. https://doi.org/10.1007/s10845-004-5892-8

Cordeau, Jean-François Gendreau, M., \& Laporte, G. (1997). A tabu search heuristic for periodic and multi-depot vehicle routing problems. Networks An Internacional Journal, 30(2), 105-119.

Cordeau, J. F., \& Maischberger, M. (2012). A parallel iterated tabu search heuristic for vehicle routing problems. Computers and Operations Research, 39(9), 2033-2050. https://doi.org/10.1016/j.cor.2011.09.021

Créput, J. C., Hajjam, A., Koukam, A., \& Kuhn, O. (2012). Self-organizing maps in population based metaheuristic to the dynamic vehicle routing problem. Journal of Combinatorial Optimization, 24(4), 437-458. https://doi.org/10.1007/s10878-011-9400-8

Dantzig, G. B., \& Ramser, J. H. (1959). The Truck Dispatching Problem. Management Science, 6(1), 80-91.

Froger, A., Mendoza, J. E., Jabali, O., \& Laporte, G. (2019). Improved formulations and algorithmic components for the electric vehicle routing problem with nonlinear charging functions. Computers and Operations Research, 104, $256-294$. https://doi.org/10.1016/j.cor.2018.12.013

Gulczynski, D., Golden, B., \& Wasil, E. (2011). The period vehicle routing problem: New heuristics and real-world variants. Transportation Research Part E: Logistics and Transportation Review, 47(5), 648-668. https://doi.org/10.1016/j.tre.2011.02.002

Laporte, G., \& Nobert, Y. (1987). Exact algorithms for the vehicle routing problem. Annals of Discrete Mathematics, 31, 147-184.

Melian, B., \& Moreno-vega, J. M. (2003). Metaheuristicas : Una visión global. January.

Méndez, A., Pontin, M., Ziletti, M., \& Chávez, L. (2005). Heurísticas Para La Resolución De Un Problema De Ruteo De Vehículos Periódico Real. Mecánica Computacional, 24(November). 
Mourgaya, M., \& Vanderbeck, F. (2007). Column generation based heuristic for tactical planning in multi-period vehicle routing. European Journal of Operational Research, 183(3), 1028-1041. https://doi.org/10.1016/j.ejor.2006.02.030

Muñuzuri, J., Domíngueza, I., Berrocal, M. A., \& Escudero, A. (2016). An allocation-scheduling heuristic to manage train traffic in an intermodal terminal. Computers in Industry, 82, 196-204. https://doi.org/10.1016/j.compind.2016.07.006

Olivera, A. (2004). Heurísticas para problemas de ruteo de vehículos. Instituto de Computacion - Facultad de Ingenieria., 63.

Orrego Cardozo, J. P., Ospina Toro, D., \& Toro Ocampo, E. M. (2016). Solución al Problema de Ruteo de Vehículos con Capacidad Limitada (CVRP) usando una técnica metaheurística. Scientia et Technica, $21(3), 225$. https://doi.org/10.22517/23447214.9013

Osman, I. H. (1993). Meta-strategy simulated annealing and Tabu search algorithms for the vehicle routine problem. Annals of Operations Research, 41(4), 421-451. https://doi.org/10.1007/BF02023004

Patiño Chirva, J. A., Daza Cruz, Y. X., \& López-Santana, E. R. (2016). A Hybrid Mixed-Integer Optimization and Clustering Approach to Selective Collection Services Problem of Domestic Solid Waste. Ingeniería, 21(2), $235-247$. https://doi.org/http://dx.doi.org/10.14483/udistrital.jour.reving.2016.2.a09

Pullen, H. and Webb, M. (1967). A computer application to a transport scheduling problem. The Computer Journal, 10(1), $10-13$.

Puras, A. M., \& Bonrostro, J. A. P. (2016). Modelo real de planificación y rutas Bi-objetivo. Equilibrio entre costes y preferencias de clientes. Recta, 17(1), 57-80.

Reyes Morales, N. (2016). Modelo de optimización de programación de rutas para una empresa logística peruana usando herramientas FSMVRPTW. Industrial Data, 19(2), 118. https://doi.org/10.15381/idata.v19i2.12847

Rocha Medina, L. B., González La Rota, E. C., \& Orjuela Castro, J. A. (2011). Una revisión al estado del arte del proble- ma de ruteo de vehículos : Evolución histó- rica y métodos de solución State of the art review of the vehicle routing problem : A historic account with solving methods Resumen. Ingeniería. Universidad Francisco José de Caldas, 16(2), 35-55.

Rodríguez-Vásquez, W. C., López-Santana, E. R., \& Méndez-Giraldo, G. A. (2016). Proposal for a Hybrid Expert System and an Optimization Model for the Routing Problem in the Courier Services. In J. C. Figueroa-García, E. R. LópezSantana, \& R. Ferro-Escobar (Eds.), Applied Computer Sciences in Engineering WEA 2016 (Vol. 657, pp. 141-152). Springer International Publishing AG. https://doi.org/10.1007/978-3-319-50880-1_13

Rodriguez, S., Correa, D., \& López-Santana, E. (2015). An Alternative Iterative Method to Periodic Vehicle Routing Problem. In S. Cetinkaya and J. K. Ryan (Ed.), IIE Annual Conference and Expo 2015 (pp. 2001-2010).

Russell, R. A. (1977). An Effective Heuristic for the M -Tour Traveling Salesman Problem with Some Side Conditions. Operational Research, 25(3), 517-524.

Russell, R. A., \& Gribbin, D. (1991). A multiphase approach to the period routing problem. Networks An Internacional Journal, 21(7), 747-765.

Schneider, K., \& Nurre, S. G. (2019). A multi-criteria vehicle routing approach to improve the compliance audit schedule for food banks. Omega (United Kingdom), 84, 127-140. https://doi.org/10.1016/j.omega.2018.05.002

Solomon, M. M. (1987). Algorithms for the Vehicle Routing and Scheduling Problems with Time Window Constraints. Operations Research, 35(2), 254-265. https://doi.org/10.1287/opre.35.2.254

Torres Prato, R., Fernando, D., \& Pérez, S. (2015). Ruteo de Vehículos desde un Centro de Distribución a una Línea de Supermercados en Barranquilla, Colombia Vehicle Routing from a Distribution Center to a Supermarket Line in Barranquilla , Colombia. Ingeniare, 10(18), 11-21.

Toth, P., \& Vigo, D. (2002). The vehicle routing problem. In Optimization (Vol. 9). SIAM. https://doi.org/10.1137/1.9780898718515

Yousefikhoshbakht, M., \& Khorram, E. (2012). Solving the vehicle routing problem by a hybrid meta-heuristic algorithm. Journal of Industrial Engineering International, 8(1), 1-9. https://doi.org/10.1186/2251-712X-8-11

Zhao, M., \& Lu, Y. (2019). A heuristic approach for a real-world electric vehicle routing problem. Algorithms, 12(2), 1-19. https://doi.org/10.3390/a12020045

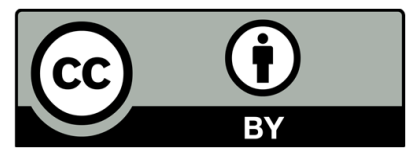

(C) 2022 by the authors; licensee Growing Science, Canada. This is an open access article distributed under the terms and conditions of the Creative Commons Attribution (CCBY) license (http://creativecommons.org/licenses/by/4.0/). 